\title{
STEREOCHEMICAL TYPES AND VALENCY GROUPS*
}

$\mathrm{T}$ HEORY and experiment agree that the arrangements in space of the covalencies of a polyvalent atom, while they are subject, from a variety of causes, to small variations seldom exceeding $5^{\circ}-10^{\circ}$, tend to conform to a quite limited number of types. Recent developments of mathematical physics have made it possible to calculate how these types are related to the electronic groups occupied by the valency electrons.

It is, however, not always possible to say which these sub-groups are, and it is in any event desirable for the chemist that he should be able to relate the spatial grouping to some more familiar property of the atom. The property here used is the size (in G. N. Lewis's sense) of the valency group of the central atom, and the number of shared electrons which it contains, together with that of the preceding (unshared) electronic group in the atom. The experimental results show the following relations.

When the valency group is less than 8 we have with a covalency of 2 a linear structure (as in $\mathrm{Cl}$ $\mathrm{Hg}-\mathrm{Cl})$ : with a covalency of 3 a plane structure with equal angles of $120^{\circ}\left(\mathrm{BF}_{3}\right)$ : with 6 electrons of which only 4 are shared, as in the vapour form of stannous chloride, probably a triangular molecule $\mathrm{Sn} / \mathrm{Cl}$.

With a complete octet the arrangement can be either tetrahedral or planar. When the covalency is less than 4 (partially shared octet), it is always derived from the tetrahedron, as in the triangular $\mathrm{OH}_{2}$ and the pyramidal $\mathrm{NH}_{3}$. The fully shared 4 -covalent octet can be of either form. When the preceding electronic group, $n$ in the grouping $(n) 8$, is 2,8 , or 18 , it is always tetrahedral. In the transitional elements where $8<n<18$, it is found that if $n$ is not much more than 8 the structure is tetrahedral,

- Substance of the Bakerian Lecture before the Royal Society delivered by Prof. N. V. Sidgwick, F.R.S., and H. M. Powell on June 27. and if it is not much less than 18, planar; but the two series overlap, and for values of $n$ of 13 to 15 and perhaps 16 , both forms occur.

When the valency group is 10 with at least 2 of them (the 'inert pair') unshared, the structure of a dicovalent atom (as in $M\left[I_{3}\right]$ ) is linear; that of the 3-covalent (as in $\mathrm{C}_{6} \mathrm{H}_{5} \cdot \mathrm{ICl}_{2}$ ) is unknown, while that of the 4-covalent decet is found in the thallous and plumbous compounds to be planar, but in tellurium tetrachloride may possibly be a distorted tetrahedron.

The peculiar 4-covalent duodecet in $\mathrm{M}\left[\mathrm{ICI}_{4}\right]$ is planar.

Covalency 5. So far as it has been examined (four different types), this has always been found to give a trigonal bipyramid.

Covalency 6. Three structures are theoretically possible: a trigonal prism, a trigonal antiprism, and a regular octahedron. Experimentally the structure is always found to be the octahedron, except in a few giant molecules such as those with the nickel arsenide lattice. The regular octahedron has been found with practically every possible size of the preceding group, as well as with the 'inert pair' of electrons.

A covalency of 7 has been examined in three or four compounds, which have two different structures, one derived from an octahedron and the other from the trigonal prism.

Covalency 8. The only compound examined, $\mathrm{K}_{A}\left[\mathrm{Mo}(\mathrm{CN})_{8}\right]$, is found (rather unexpectedly) to have a dodecahedral arrangement of the $8 \mathrm{CN}$ groups.

Nearly (but not quite) all the structures can be even more simply related to the size of the valency group by assuming that the mean positions of the electron pairs in this group are the same whether they are shared or not, the structure being linear for 4 electrons, plane symmetrical for 6, either tetrahedral or plane for 8 , a trigonal bipyramid for 10 , and an octahedron for 12 .

\section{CONCENTRIC CONDUCTOR TYPE OF HIGH-VOLTAGE ALTERNATORS}

\begin{abstract}
A
PAPER on "Operating Experience with High Voltage Alternators" by W. D. Horsley, of Messrs. C. A. Parsons and Co., Ltd., which was to have been read and discussed before the Institution of Electrical Engineers, has now been published in the Journal of the Institution of April. It was read and discussed before five local centres at various dates, and the discussions at these centres have been included.

The first high-voltage alternator of the concentric type was commissioned in August 1928, the pressure chosen being 33 kilovolts. The earlier history of this machine and its successful operation have been fully described by C. A. Parsons and J. Rosen and was published in 1929 in vol. 67 of the Journal. Since it was installed at the North Metropolitan Power Station, it has worked smoothly, the maintenance
\end{abstract}

costs being negligible although the conditions of operation were more difficult than the average in the early years of its life. There are now twenty-one machines of this type in service, and a review of some of the difficulties experienced is first given. The second machine built had an output of $25,000 \mathrm{kw}$. at a pressure of $33 \mathrm{kv}$, and was installed in the Brimsdown Power Station in 1932. But after being put into service, a breakdown occurred on the third day owing to the failure of a slot insulating tube and the core. This accident demonstrated the rapidity with which a bar can be replaced in the concentric type of winding. Soon afterwards, improved methods of inspection and testing, including the measurement of the dielectric losses of individual bars, were introduced, and the possibility of a faulty conductor being fitted in an alternator is now very remote. 